Max-Planck-Institut für demografische Forschung

Max Planck Institute for Demographic Research

Konrad-Zuse-Strasse 1 - D-18057 Rostock = Germany = Tel +49 (0) 3812081 - 0 - Fax +49 (0) 3812081 - 202 - www.demogr.mpg.de

MPIDR Working Paper WP 2019-015 I August 2019

\title{
The population of centenarians in Brazil: historical estimates \\ from 1900 to 2000
}

Marília R. Nepomuceno I nepomuceno@demogr.mpg.de Cássio M. Turra

This working paper has been approved for release by: Alyson van Raalte (vanRaalte@demogr.mpg.de), Head of the Research Group:Lifespan Inequalities.

(C) Copyright is held by the authors.

Working papers of the Max Planck Institute for Demographic Research receive only limited review. Views or opinions expressed in working papers are attributable to the authors and do not necessarily reflect those of the Institute. 


\title{
The population of centenarians in Brazil: historical estimates from 1900 to 2000
}

\author{
Marília R. Nepomuceno*1 and Cássio M. Turra ${ }^{2}$ \\ ${ }^{1}$ Max Planck Institute for Demographic Research, Rostock, Germany \\ ${ }^{2}$ Centre for Development and Regional Planning - CEDEPLAR - Federal University of Minas \\ Gerais, Belo Horizonte, Brazil
}

\begin{abstract}
Does anyone know the exact number of centenarians in Brazil? Since the nineteenth century, the census has provided the number of 100-year-olds in one of the most populous countries worldwide. In 1900, 4,438 individuals reported themselves to be centenarians, and 100 years later, 24,576 centenarians were recorded in the census. Due to data quality issues, we are skeptical about the real growth of the recorded population in the census. Therefore, we produce new statistics of the centenarian population through the variable-r method combined with different mortality models. We offer a set of estimates of the most likely number of centenarians in Brazil over the period 1900-2000. There was virtually no centenarian at the beginning of the twentieth century, and only in the 1990s, the centenarian population surpassed 1,000 individuals. Our estimates confirm an extensive over-enumeration of centenarians in census records since 1900. The good news is the improvement in census data collection over time.
\end{abstract}

Keywords: age exaggeration, data quality, old-age mortality, centenarians.

\footnotetext{
*Corresponding Author. E-mail: nepomuceno@ demogr.mpg.de Address: Konrad-Zuse-Str. 1, 18057 Rostock, Germany

Tel: +49 381 2081-223; Fax: +49 381 2081-280
} 


\section{Introduction}

The number of people reaching the age of 100 has called the attention of scientists, including many demographers. In 1990, nearly 90,000 centenarians were living in the world. Over the last 25 years, this number increased five times, reaching more than 410,000 people in 2015 (U.N. 2019). Not surprisingly, given the historical and regional patterns of survival gains, there is a concentration of elderly populations in wealth low-mortality regions. However, between 1990 and 2015, the number of centenarians increased by $10 \%$ more in middleincome than high-income countries, suggesting the centenarian trend may be spreading to other regions.

Vaupel and Gowan (1986) were among the first authors to foresee the growth in the number of centenarians by simulating scenarios of survival gains in the United States. A few years later, Thatcher (1992) reported an increasing number of centenarians in England and Wales, particularly after World War II. Since then, other studies have examined trends and patterns of the centenarian population in several low-mortality countries (Barbi et al. 2018; Drefahl et al. 2012; Jdanov et al. 2008; Kestenbaum and Ferguson 2005; Leeson 2017; Medford et al. 2019; Poon and Cheung 2012; Rau et al. 2008; Robine, Saito, and Jagger 2009; Robine et al. 2010; Robine and Saito 2003; Skytthe and Jeune 1995; Thatcher 2001; Wilmoth 1995; Wilmoth and Lundström 1996)

The interest in the factors that have driven the proliferation of centenarians has been increasing as well. According to Preston and Coale (1982), population growth is due to a combination of changes in births, migration, and mortality rates. In the case of the centenarian population, Vaupel and Jeune (1995) emphasized the impact of mortality decline on the growing number of centenarians. They found that the proliferation of centenarians is mainly due to improvements in survival from ages 80 to 100 in low-mortality countries. Other authors have also stressed the role of declines in late-adult mortality, and postponement of 
age-at-death, to determine the size of the centenarian population (Kannisto et al. 1994; Robine and Paccaud 2005; Robine and Cubaynes 2017). In Japan, where the distribution of deaths strongly shifted to older ages between 1980 and 2000 (Robine and Cubaynes 2017), the number of centenarians increased fourteen-fold, from 913 to 13,036 (Robine and Saito 2003).

In the decades to come, we can also expect a steady proliferation of centenarians in middleincome countries, where the mortality transition - from infant and early-adult to late-adult and old ages - started later but it is in progress. There have been already some reports about the multiplication of the number of centenarians in China (Wang, Zeng, Jeune, \& Vaupel, 1998), Cuba (Calzadilla et al. 2013), and in other countries like Mexico, Russia and Poland (Herm, Cheung, \& Poulain, 2012). In Brazil, according to the census data, there were almost twice as many centenarians in $2010(24,236)$ than in 1991 (13,296) (IBGE 1991; 2010). However, confounding data errors have precluded a more in-depth examination of the determinants of this type of demographic trends in middle-income countries, where the vital registration systems are usually weaker. The main reason is the low quality of population counts at older ages due to coverage and content errors, including age misreporting (Turra 2012).

The study of the relationship between the number of centenarians recorded in the census and data quality issues is not new and has received extensive attention also in wealthier nations. For example, in the United States, estimates of the number of centenarians showed that the census population was overestimated by about three times in 1960 (Myers 1966). Also, for the U.S., some studies have used death statistics and extinct generations methods to confirm the existence of data quality issues at older ages, particularly for some population subgroups such as African Americans (Siegel and Passel 1976). The norm has been age overstatement in census data relative to deaths, although the magnitude of the exaggeration has varied over time (Elo and Preston 1994; Rosenwaike 1979; Rosenwaike and Logue 1983). Not only in the 
U.S. but also the Canadian census has over-counted the number of centenarians, particularly the number of semi-supercentenarians (Bourbeau \& Lebel, 2000).

In the case of Brazil, seventy years ago, Mortara (1949) was already very skeptical about the quality of the population enumerated by age in the 1920 and 1940 Census, particularly at older ages. He projected backward the number of births and the probabilities of surviving for different cohorts to estimate what would have been the number of native-born Brazilians by age in both years and compared them to the census figures. Concerning the centenarians, the results were astonishing: he estimated about six and nine people, respectively, for 1920 and 1940, whereas both censuses counted more than six thousand individuals.

Decades later, the official Brazilian figures are still suspicious. A simple comparison of the prevalence of centenarians shows that in the 1991 Census, it was about $30 \%$ higher $(0.94$ per $10,000)$ than the rate found, for example, in Sweden $(0.69$ per 10,000$)$ despite the 1.5 years lower life expectancy at age 70 in Brazil (HMD 2019; IBGE 2010). In 2000, the prevalence increased to 1.45 per 10,000 , but reduced to 1.27 per 10,000 in 2010 , eventually becoming lower than the Swedish rate (1.71 per 10,000). This apparent erratic behavior on the prevalence rates in Brazil possibly reflects improvements in age reporting across censuses and birth cohorts. Tests of consistency have confirmed the data quality issues among older Brazilians. Following the studies developed in the U.S., Gomes and Turra (2009) compared the number centenarians in the 1991 Brazilian census with extinct generation estimates based on the number of cohort deaths in the following years. The results show significant discrepancies between the two data sources: about three times more centenarians in the census than registered deaths. Unfortunately, the death files are also not immune to both coverage and content errors, and it remains unclear what it is the most likely size of the centenarian population in Brazil. 
The absence of reliable estimates of the centenarian population in populous countries, which have witnessed rapid demographic transitions but lack accurate data, prevents a more comprehensive discussion on the dynamics of these longevous subgroups beyond the limited set of lowest mortality countries. It also hinders local governments from planning policies to reach the demands of a growing old age population in places that usually face stricter family and public budget constraints. It is therefore valuable to estimate what would have been the probable evolution of the Brazilian centenarian population over the decades. In the following, we use variable- $r$ relations (Horiuchi and Preston 1988; Preston et al. 2001) to estimate the centenarian population from the combination of different mortality schedules. Our results show a range of estimates which may reasonably be expected to bracket the correct number of centenarians over 1900-2000. Moreover, we point out the differences between our set of estimates and the reported number of centenarians in the Brazilian censuses between 1900 and 2000. We hope our findings stimulate the statistical agencies in Brazil to improve even further the process of obtaining information about older populations.

\section{Data and Methods}

\section{The Variable-r Method}

Variable- $r$ relations can be of great value in the estimation of population measures when data are missing or are of bad quality. Preston and Coale (1982) show that the number of individuals from different age groups in the same year is related in terms of survival probabilities and demographic differences, which are reflected in the age-specific population growth rates. Following the discrete formula detailed in Preston et al. (2001), we estimated the number of centenarians in Brazil by sex, for the years that correspond to the census' years 1900, 1920, 1940, 1950, 1960, 1970, 1980, 1990 and 2000:

$$
{ }_{n} N_{x}={ }_{n} N_{y} e^{-\int_{0}^{x} \bar{r}(a) d a}{ }_{x-y} p_{y}
$$


where ${ }_{n} N_{x}$ is the population at the older age group at the census date, ${ }_{n} N_{y}$ is the population at a younger age group at the census date, $\bar{r}(a)$ is the mean age-specific growth rate over time intervals, and ${ }_{x-y} p_{y}$ is the probability of surviving from ages $y$ to $x$. We applied Eq.1 in two steps to estimate the total number of centenarians. First, we calculated the population 100-109 years old, and next, the number of individuals 110 to 119 years old. We assumed no individual survived to ages beyond 119 in Brazil during the period of analysis.

\section{The (Lower Limit) Age y}

We relate the centenarian population to the number of individuals aged $y$ to $y+n$. Thus, as a first step, we must define age $y$ in Eq.1. Given the relevance of improvements of the late-adult survival to the proliferation of centenarians (Robine and Cubaynes 2017; Vaupel and Jeune 1995) and because age overstatement tends to increase with age in Brazil (Agostinho 2009) and elsewhere, we estimated the centenarian population from the number of fifty-year-olds. Since census data are not free of age misreporting, we used 10-year-wide age intervals to smooth any major inconsistencies and drew the number of people in the age group 50-59 from each successive census collected in Brazil (BRASIL 1927; BRASIL 1928; IBGE 1950; IBGE 1956; IBGE 1960; IBGE 1973; IBGE 1981; IBGE 1994; IBGE 2001; IBGE 2011). Although we believe this is the best choice for the parameter in Eq.1, to mitigate arbitrariness, we also ran sensitive analyses, described below, by varying the lower age group and the corresponding population and mortality measures.

\section{Age-specific Growth Rates}

Next, we estimated the set of age-specific growth rates above age $y$, for every intercensal period. Even if the size and the age distribution of the population at ages 50 and older is biased in the census, we can apply the variable- $r$ relations as far as the pattern of data errors does not change significantly over time, affecting the age-specific growth rates (Preston et al. 2001). Nevertheless, to mitigate any potential bias in the growth rates from the variation of 
census data quality over time, which seems to have occurred at the oldest ages, we estimated annualized age-specific growth rates for ten-year age groups up to age group 80-89. After age 89 , rather than using age-specific growth rates, we replaced them with the annualized mean growth rate for ages 90 and above. We tried different open-ended age intervals in the sensitivity analyses, as we explain below.

Because we wanted to make estimates separately for each census year, rather than for intercensal periods, we used two intercensal growth rates that are centered on each census date to calculate the mean growth rates. For example, for the age-group 70-79 in 2000, we used the mean growth rate at ages 70 to 79 in 1991-2000 and 2000-2010. Also, because in the first forty years of the analysis, census observations are separated by twenty years (1900-1920 and 1920-40), we calculated annualized twenty-year age-specific growth rates. Moreover, we assumed that age-specific growth rates for the period 1900-1920 apply to 1900 .

\section{Conditional Probability of Surviving}

The third parameter in Eq.1 is the conditional probability of surviving. To estimate the number of centenarians, we computed life table survivorship ratios from ages 50-59 to age groups 100-109 and 110-119. Both coverage and content data errors (Agostinho 2009; Gomes and Turra 2009; Horta 2012) preclude us from estimating unbiased mortality rates at older ages directly from deaths and census data. In Brazil, as in many other countries where data are deficient, age misreporting is probably the main reason why death rates increase slower with age than in high-quality data countries (Coale and Kisker 1986; Dechter and Preston 1991; di Lego, Turra, and Cesar 2017; Preston, Elo, and Stewart 1999; Turra 2012). Therefore, to mitigate data quality issues, we applied and compared different methodological strategies to estimate the mortality functions, including (i) Coale-Demeny Life Table Models for the years 1900 to 2000; and (ii) three different mathematical representations of mortality - Gompertz, Weibull, and Kannisto models - for the year 2000. 
As a first step, we calculated the survivorship ratios from the UN version of the CoaleDemeny (CD) Model Life Tables, which extended the original mortality levels to include life expectancy at birth up to 100 years (U.N. 2017). We decided not to choose one specific model from CD (South, North, West, and East). Instead, we offer estimates based on all four regions. To select the correct mortality level for each regional pattern in every census year, we used two different and complementary parameters: (i) the life expectancy at birth and (ii) the life expectancy at age 50. The life expectancy at birth $\left(e_{0}\right)$, summarizes mortality conditions for all ages, and thus, it is less affected by data quality issues at older ages. Moreover, it is probably the best measure available to capture historical mortality levels in Brazil. We used $e_{0}$ calculated by the Brazilian Census Bureau (IBGE 1981; IBGE 2017), for all years (1900 to 2010). Next, we use life expectancy at age 50 for all the years since 1940 (IBGE 2000; IBGE 2010; IBGE 2017). It is an index of adult mortality and is more likely to be associated with the size of the centenarian population. However, it can be more affected by data errors at later ages, and it is not available from 1900 to 1930 .

In addition to the estimates based on CD Model Life Tables, we calculated survival functions by fitting three mathematical functions to Brazilian mortality rates: Gompertz, Weibull, and Kannisto. There is a general agreement that mortality increases exponentially from mid-adult to ages $80-90$, as described by the Gompertz law. However, there is not a consensus regarding the mortality trajectory at the most advanced ages (Barbi et al. 2018; Gampe 2010; Gavrilova and Gavrilov 2015; Gavrilov and Gavrilova 2011; Robine and Vaupel 2001; Vaupel et al. 1998). Some studies suggest that the exponential growth of mortality with age is followed by a period of deceleration, with slower rates of mortality increase at the oldest ages (Barbi et al. 2017; Gampe 2010; Robine and Vaupel 2001; Vaupel et al. 1998). Conversely, another group of researchers has contended that mortality deceleration in later life is a consequence of poorer data quality at older ages, and that in reality mortality continues to grow exponentially at the highest ages (Gavrilov and Gavrilova 2011; Gavrilova and Gavrilov 2015). Due to this 
disagreement, we decided to offer estimates for the number of centenarians in Brazil from the application of the three mortality models.

To estimate the parameters of the mathematical models we used official life tables estimated by the Brazilian Institute of Geography and Statistics (IBGE 2013). We fitted the mathematical models to the death rates for the ages 70 to $90+$ and then extrapolated the results to the advanced ages. To avoid adding bias from mortality data errors, which were more prevalent in the earlier years, we limited the mathematical estimates to the year 2000 .

\section{Sensitivity Analysis}

As we stressed before, to test for the robustness of our results and offer a range (upper and lower limits) of estimates, we ran sensitivity analyses by varying the inputs of the Eq.1. First, we changed age $y$ by starting the calculations from ages $60-69$, instead of just 50-59. As we varied age $y$, we had to obtain the corresponding population estimates from the census data and the life table survivorship ratios for each new age range. Second, in addition to applying the annualized mean growth rate for ages 90 and above, we tested for two different openended age intervals: 80 and above, and 100 and above.

After varying the lower limit age $y$, the configuration of age-specific growth rates in the openended age interval and the mortality schedules, we produced 184 estimates of the centenarian population by sex between 1900 and 2000 . We present and discuss absolute sizes, sex ratios, and prevalence rates for the Brazilian centenarian population, as well as the life table survivorship ratios from ages 50-59 to 100-109 under the scenarios previously discussed. We compare some of them to the measures calculated directly from census data.

\section{Cohort Estimates}

Variable- $r$ estimates are useful to relate the number of centenarians to the number of younger adults in the same year, allowing us to estimate the population of Brazilian centenarians over a more extended period. However, there is no guarantee that the age-specific growth rates are 
not biased because of changes in census coverage and content errors over time. Therefore, we calculated another set of results based on cohort estimates for the second half of the twentieth century. We reconstructed the possible mortality trajectories for cohorts aged 50 to 59 and 60 to 69 years old in 1900 to 1950 and calculated the number of surviving individuals at ages 100-119 in every decade from 1950 to 2000. Because there are no census data in 1910 and 1930, we interpolated the population at ages 50 to 69 in those years based on the observations from 1900, 1920 and 1940 censuses. We limited our cohort analysis to the life tables calculated from CD Model Life Tables (West Model) since the objective is only to test for potential discrepancies between period and cohort estimations. In order to approximate the cohort mortality functions, we apply the geometric mean of life table survivorship ratios at the beginning and end of each intercensal period and take the corresponding age-period estimates.

\section{Results}

Before examining the indirect estimates of the centenarian population, it is essential to introduce the problem of over-enumeration of older people in Brazil. Fig.1 compares the prevalence rates (per 10,000) of centenarians recorded in the Brazilian censuses with prevalence rates for a set of high-longevity countries (HLC). The graph also displays the association between life expectancy at birth and the prevalence rates for each one of the countries. We drew population and mortality data for the HLC from the Human Mortality Database (HMD, 2019).

[Fig.1 about here]

As expected, life expectancy was lower in Brazil than in the HLC, for both men and women. However, particularly in the past, the prevalence rates of centenarians in Brazil were considerably higher than in the HLC. For instance, there was virtually no centenarian in Sweden in 1900 and 1910, while in Brazil, the prevalence rate reached levels higher than two per 10,000 in 1900, according to the official figures. Over the twentieth century, as mortality 
declined, the prevalence of centenarians consistently increased in the HLC. In Sweden, for example, the prevalence of female centenarians augmented by about one hundred-fold over the 110 years, and in Japan, it increased by about three hundred-fold between 1950 and 2010 . The prevalence rates for women in these two countries are now above two (Sweden) and five (Japan) per 10,000. At the same time, according to the Brazilian official statistics, the prevalence of centenarians took the opposite direction in Brazil. In the case of women, it decreased from 2.83 in 1900 to 1.75 per 10,000 in 2010, despite an increase of about 40 years in life expectancy at birth. For men, the decline in the prevalence rate was more substantial, ranging from 2.32 to 0.78 per 10,000 .

The historical analysis of Brazilian census data raises serious questions about the quality of enumeration at older ages and suggests the need for new statistics of the centenarian population. As aforementioned, we produced 184 different indirect estimates, which are available upon request, based on the combination of several mortality models and parameters for Eq.1. Table 1 below summarizes the number of centenarians by sex, for each year, by showing the average, minimum, and maximum population calculated from the main set of indirect estimates. We cannot show the official figures for 1970 because the census data available in that year preclude us from separating the ninety-year-olds from centenarians.

[Table 1 about here]

The indirect estimates indicate that there was probably no centenarian in the first two decades of the twentieth century in Brazil. The number of centenarians grew little until 1940 when the mortality transition started to affect both population growth rates and the chances to reach ages 100 and older. It would have been only after 1960 that the number of centenarians had surpassed 100 individuals, reaching some value around 1,000 (between 200 and 2,000) centenarians in 2000, of which approximately $80 \%$ were women. Between 1900 and 2000, the 
sex ratio based on our estimates considerably declined from 0.62 to 0.24 , because of an increasing gender gap in mortality over the years.

The estimates also confirm an extensive over-enumeration in the census records (Table 1). According to the census data, 4,438 centenarians were living in Brazil in 1900, from which $46 \%$ were men. This census estimate is so large that it was not even reached a century later, according to our most optimistic scenario. Also, the sex ratio of 0.86 in the 1900 census is surprising given the female mortality advantage, particularly at adult ages. This result shows that in the past, the over-enumeration of older groups was more frequent among men than women.

The implausibility of the census data becomes even more evident in Fig.2. We calculated ratios of the centenarian population in the census data to all indirect measures based on the variable- $r$ method and the cohort estimates. The declining ratios for both men and women confirm the implausible numbers in the past and the improvement of census data over the years. In the first decades of the twentieth century, prevalence rates based on indirect estimates were a few thousand times lower than the ones calculated from the censuses. In 2000 , the mean ratio (census data/estimates) was significantly lower than in the past but still higher than 10.

[Fig.2 about here]

Indirect estimates of the centenarian population also involve uncertainty. Fig. 2 reveals the sensitivity of the centenarian population indirectly estimated due to changes in the parameters of Eq.1. Changing the age $y$ (lower age limit) from 50-59 to 60-69 or varying the open-ended age group (from $90+$ to $80+$ and $100+$ ) to calculate the age-specific growth rates have only minor impacts on the estimated number of centenarians. Depending on the parameter changed, the average relative difference calculated for all the years and mortality models together varies from less than four to about $19 \%$ among men, and from four to about to about 
$15 \%$ among women. Consistently, cohort reconstructions based on the West family of the CD Life Tables are also comparable to the variable- $r$ estimates. Among men, from 1950 to 2000, the average number of male centenarians would be only $11 \%$ higher using period instead of cohort measures. Among women, the average difference is only about $6 \%$, for the years 1950 to 1990 . However, for the year 2000, there is a more considerable discrepancy. We estimated 425 and 258 women, respectively, in the period and cohort analyses. This isolated result may reflect a combination of factors, including the inadequacy of the life table model, the increasing gender differences in mortality in more recent years, and changes in census coverage at older ages between 2000 and 2010 that impacted the age-specific growth rates.

By analyzing Table 1 and Fig. 2 together, we see that the most substantial portion of the variation in our results comes from the choice of the adult mortality model. For instance, in 1960 , the number of centenarians can vary from 12 to 87 only due to changes in the mortality schedules. Therefore, the idea of providing a set of population estimates by varying the mortality models is not only to uncover our ignorance about the actual mortality function at older ages in Brazil but also to measure the extent to which census data are out of range. In Fig.3, we show how life table survivorship ratios from ages 50-59 to 100-109 have changed since 1900, according to each mortality age schedule. The ratios derived from the North, Kannisto, and Weibull model are the highest, since $(i)$ the North Model reflects conditions that are typical of countries that experience lower mortality at older ages, (ii) the Kannisto Model follows the logistic form at advanced ages, and (iii) the Weibull Model is an intermediate pattern between the exponential and logistic mortality increases at older ages. The lowest survival estimates are those calculated from the South and East Model, which is not surprising because they reflect conditions of countries with higher mortality at advanced ages. The difference in the ratios estimated between the highest and the lowest models can get as high as ten times and seven times, respectively, for men and women in 2000. 
[Fig.3 about here]

Regardless of the mortality model adopted, survival gains have been particularly high among women. For example, the chances of women surviving to ages 100-109 from ages 50-59 improved 34-fold, between 1900 and 2000, according to the West Model. However, these gains were not enough to explain the large number of centenarians in the Brazilian censuses. The actual probabilities of surviving would need to be ten to one thousand times higher than the survival curves adopted in the current work, depending on the year and sex, for census records to be real.

\section{Discussion}

There is a general belief in Brazil that the centenarian population has been increasing very rapidly over the last decades. According to the census data, the centenarian population grew two and a half times between 1960 and 2000 and currently comprises more than 24,000 individuals. Whereas the Brazilian population is indeed getting older faster than in many wealthier regions, the estimated centenarian population is probably significantly smaller than the number of individuals counted by the census, having increased from fewer than 100 individuals in 1960 to between 200 and 2,000 people in the year 2000. The slower growth of the centenarian population in the census than predicted by our estimates suggests there have been improvements in data collection over time. Also, the much higher census sex ratios reinforce the hypothesis of over-enumeration of centenarians, particularly men.

Our indirect estimates based on variable- $r$ relations are not immune to errors. Age-specific growth rates in Brazil may vary over time due to changes in census data quality, affecting the estimates of the population size at older ages. However, sensitivity analyses, including cohort estimates, indicated that any errors from the methodology are probably not substantial. What affects population estimates at old ages is the choice of the mortality model. To minimize the lack of high-quality mortality data at advanced ages in Brazil, we compared estimates from 
different mortality schedules and concluded that unless adult age patterns of mortality are very atypical in Brazil, the number of centenarians in the census records are incompatible with the prevailing adult mortality levels in the country.

Mortara (1949) was the first demographer to worry about the poor quality of the population enumerated at older ages in the Brazilian censuses, anticipating what would be a crucial subject decades later. Ours is the first study to provide a systematic comparison between indirect estimates and census records of centenarians over a century in Brazil, although other recent studies have also cast light on issues related to the enumeration of centenarians. As aforementioned, Gomes and Turra (2009) found that the number of centenarians in census records was triple those in death files in the year 1991. Here, we showed that the number of centenarians is not only substantially smaller than census records but also lower than the number of deaths registered at ages 100 and older. Whereas it is not surprising that age misreporting affects the quality of both census data and death files, the bias is proportionally more extensive in the census records resulting in artificially lower mortality rates at older ages, as recognized by (Preston, Elo, and Stewart 1999) and examined by Turra (2012) for Brazil.

The evolution of the population of Brazilian centenarians across the decades, as measured by the census records, is odd, because of significant data improvements that have occurred in each new data collection. This inaccurate time trend seems to reflect in the estimates prepared by the U.N. (2019). According to them, the number of centenarians decreased from almost nine thousand in 1950 to fewer than 100 individuals in 1970, increasing after that. Therefore, we believe the U.N. figures for the 1950s and 1960s are wrong, although they are significantly more consistent with (somewhat higher than) our estimates for the period 19702000. Also, according to the U.N. (2019) projections, the population of Brazilian centenarians will only reach the number recorded in the 2000 census (about 25,000 individuals) in the year 
2025, surpassing 100,000 and 1,000,000 cases, respectively, after 2035 and 2085. The estimation of future trends still needs more scrutiny, since the correct age patterns of mortality at adult ages in Brazil remain a puzzle. Fortunately, we expect the quality of age reporting at older ages to improve over the next decades, with the educational transition and the consolidation of the vital registration systems. The accurate measurement of population and deaths at adults ages in Brazil will become a much smaller problem in a few decades.

\section{Acknowledgement}

We thank Samuel H. Preston for his helpful comment on the variable- $r$ method. We also thank Andrew Noymer, Simone Wajnman, José Alberto de Carvalho, Bernardo Queiroz, Marcos Gonzaga, Miriam Ribeiro, Eduardo Rios-Neto, Jim Oeppen, Enrique Acosta, Ugofilippo Basellini and Alyson van Raalte for suggestions and comments. This present study was supported by the European Research Council [grant number 716323], by the Brazilian Graduate Studies Coordinating Board (Capes, Code 001), which funds the Demography Program at the Federal University of Minas Gerais, and the Brazilian National Research Council (CNPq). 


\section{References}

Agostinho C. S. (2009). Estudo sobre mortalidade adulta, para Brasil entre 1980 e 2000 e Unidades da Federação em 2000: uma aplicação dos métodos de distribuição de mortes [Adult Mortality in Brazil between 1980 and 2000, and in its regions in 2000 by using death distribution methods]. Belo Horizonte: Universidade Federal de Minas Gerais, Centro de Desenvolvimento e Planejamento Regional (CEDEPLAR).

Barbi, E., Lagona, F., Marsili, M., Vaupel, J. W., \& Wachter, K. W. (2018). Demography of longevity pioneers. Science, 360(6396), 1459-1461.

Bourbeau, R., \& Lebel, A. (2000). Mortality statistics for the oldest-old. Demographic Research, 2(2), 1-36.

BRASIL, Ministerio da Agricultura, Industria e Commercio (1927). Annuario estatistico do Brazil 1908-1912 [Brazilian Statistical Yearbook 1908-1912]. Rio de Janeiro: Directoria Geral de Estatistica, (1-3), 1916-1927.

BRASIL, Ministerio da Agricultura, Industria e Commercio (1928). Recenseamento do Brazil realizado em 1 de setembro de 1920: população [Brazilian census conducted in $1^{\text {st }}$ of September 1920]. Rio de Janeiro: Directoria Geral de Estatistica, 4(2), 1-925.

Calzadilla, E. C., Fonseca, G.M, Borroto, M. \& Martinez, C.P. (2013). Characterization of the nutritional status of the Cuban centenarian population. Revista Cubana de Investigaciones Biomédicas, 31(4), 459-466.

Coale, A. J., \& Kisker, E. E. (1986). Mortality Crossovers: Reality or Bad Data. Population Studies, 40(3), 389-401.

Dechter, A. R., \& Preston, S. H. (1991). Age misreporting and its effects on adult mortality estimates in Latin America. Population Bulletin of the United Nations, (31-32), 1-16.

di Lego, V., Turra, C. M., \& Cesar, C. (2017). Mortality selection among adults in Brazil: The survival advantage of Air Force officers. Demographic Research, 37(1), 1339-1350.

Drefahl, S., Lundström, H., Modig, K., \& Ahlbom, A. (2012). The era of centenarians: mortality of the oldest old in Sweden. Journal of Internal Medicine, 272(1), 100-102.

Elo, Irma T., \& Preston, S. H. (1994). "Estimating African-American Mortality from Inaccurate Data. Published by: Springer on Behalf of the Population Association of America, $31(3), 427-58$.

Gampe, J. (2010). Human mortality beyond age 110. In: Meier H. et al. (Eds.). Supercentenarians. Demographic Research Monographs. Heidelberg, Springer.

Gavrilov, L. A., \& Gavrilova, N. S. (2011). Mortality Measurement at Advanced Ages: A Study of the Social Security Administration Death Master File. North American Actuarial Journal, 15(3), 432-447.

Gavrilova, N. S., \& Gavrilov, L. A. (2015). Biodemography of old-age mortality in humans and rodents. Journals of Gerontology - Series A Biological Sciences and Medical Sciences, 70(1), 1-9.

Gomes, M. M. F., \& Turra, C. M. (2009). The number of centenarians in Brazil: Indirect estimates based on death certificates. Demographic Research, 20(20), 495-502. 
Herm, A., Cheung, S. L. K., \& Poulain, M. (2012). Emergence of oldest old and centenarians: demographic analysis. Asian Journal of Gerontology \& Geriatrics, 7(1), 19-26.

Human Mortality Database (2019). University of California, Berkeley (USA), and Max Planck Institute for Demographic Research (Germany). Available at www.mortality.org or www.humanmortality.de (data downloaded on $1^{\text {st }}$ of May 2019).

Horiuchi, S. and Preston, S. H. (1988). "Age-Specific Growth Rates: The Legacy of Past Population Dynamics". Demography 25 (3): 429-441.

Horta, C.J.G. (2012) Idade Declarada nos Censos Demográficos e a Qualidade da Informação [The reported age in censuses and data quality]. In: Encontro Nacional de Estudos Populacionais, 2012, Águas de Lindóia/SP - Brasil. Anais. Belo Horizonte: ABEP, 2012.

Instituto Brasileiro de Geografia e Estatistíca (1950). Recenseamento Geral do Brazil 1 de setembro de 1940 [Brazilian census conducted in the $1^{\text {st }}$ of September 1940]. Rio de Janeiro. Vol 2.

Instituto Brasileiro de Geografia e Estatistíca (1956). Brasil Censo Demográfico de 1950 [The 1950 Brazilian Census]. Rio de Janeiro. Vol 1.

Instituto Brasileiro de Geografia e Esstatistíca (1960). Censo Demográfico de 1960 [The 1960 Brazilian Census]. Rio de Janeiro. Vol 1.

Instituto Brasileiro de Geografia e Estatistíca (1973). Censo Demográfico de 1970 [The 1970 Brazilian Census]. Rio de Janeiro. Vol 1.

Instituto Brasileiro de Geografia e Estatistíca (1981). Sinopse preliminar do Censo Demográfico de 1980 [Premilimary results of the 1980 Brazilian Census]. Rio de Janeiro Vol 1 .

Instituto Brasileiro de Geografia e Estatistíca (1994). Censo Demográfico 1991 [The 1991 Brazilian Census]. Rio de Janeiro. Vol 1.

Instituto Brasileiro de Geografia e Esstatistíca (2001). Censo Demográfico 2000: características da população e dos domicílios: resultados do universo [The 2000 Brazilian Census: population and housing charactersitcs]. Rio de Janeiro. Vol 1.

Instituto Brasileiro de Geografia e Estatistíca (2010). Observações sobre a evolução da mortalidade no Brasil: o passado, o presente e perspectivas [The evolution of mortality in Brazil, past, present and perspectives]. Rio de Janeiro. Vol 1.

Instituto Brasileiro de Geografia e Estatistíca (2011) Censo Demográfico 2010: características da população e dos domicílios: resultados do universo [The 2010 Brazilian Census: population and housing charactersitcs]. Rio de Janeiro Vol 1.

Instituto Brasileiro de Geografia e Estatistíca (2011) Censo Demográfico 2010: características da população e dos domicílios: resultados do universo [The 2010 Brazilian Census: population and housing charactersitcs]. Rio de Janeiro Vol 1.

Instituto Brasileiro de Geografia e Estatistíca (2013). Projeção da população do Brasil por sexo e idade para o período 2000/2060 [Population projection by age and sex in Brazil from 2000 to 2060]. Rio de Janeiro. 
Jdanov, D. A., Jasilionis, D., Soroko, E. L., Rau, R., \& Vaupel, J. W. (2008). Beyond the Kannisto-Thatcher Database on Old Age Mortality: an assessment of data quality at advanced ages. IDEAS Working Paper Series from RePEc, 49(0).

Kannisto, V., Lauritsen, J., Thatcher, A. R., \& Vaupel, J. W. (1994). Reductions in Mortality at Advanced Ages: Several Decades of Evidence from 27 Countries. Population and Development Review, 20(4), 793-810.

Kestenbaum, B. M., \& Ferguson, B. R. (2005). Number of Centenarians in the United States 01/01/1990, 01/01/2000, and 01/01/2010 Based on Improved Medicare Data. Paper presented at Population Association of America, Philadelphia, Pennsylvania, March 31 - April 22005.

Leeson, G.W. (2017) The impact of mortality development on the number of centenarians in England and Wales. J Pop Research 34(1), 1-15

Medford, A., Christensen, K., Skytthe, A., \& Vaupel, J. W. (2019). A Cohort Comparison of Lifespan After Age 100 in Denmark and Sweden: Are Only the Oldest Getting Older? Demography, 56(2), 665-677.

Mortara, G. (1949). Comparação entre os números dos brasileiros natos, apurados pelos censos de 1940 e de 1920, e os calculados conforme determinadas hipóteses acêrca da população, da natalidade e da mortalidade [Comparison between the number of native-born Brazilians in the 1940 and 1920 census and the numbers derived from assumptions regarding the population, births and mortality]. Revista Brasileira de Estatística, 39.

Myers, R. J. (1966). Validity of Centenarian Data in the 1960 Census. Demography, 3(2), 470-476.

Poon, L. W., \& Cheung, S. L. K. (2012). Centenarian research in the past two decades. Asian Journal of Gerontology \& Geriatrics, 7(1), 8-13.

Preston, S. H. and Coale, A. J. (1982)."Age Structure, Growth, Attrition, and Accession: A New Synthesis". Population Index 48 (2): 217-259.

Preston, S. H., Elo, I. T., \& Stewart, Q. (1999). Effects of age misreporting on mortality estimates at older ages. Population Studies, 53(2), 165-177.

Preston, S. H., Heuveline, P., Guillot M. (2001). "Demography: measuring and modeling population processes". Oxford: Blackwell Publishers Ltd

Rau, R., Soroko, E., Jasilionis, D., \& Vaupel, J. W. (2008). Continued reductions in mortality at advanced ages. Population and Development Review, 34(4), 747-768.

Robine, J.-M., \& Vaupel, J. W. (2001). Supercentenarians: slower ageing individuals or senile elderly? Experimental Gerontology, 36(4-6), 915-930.

Robine, J. M., Cheung, S. L. K., Saito, Y., Jeune, B., Parker, M. G., \& Herrmann, F. R. (2010). Centenarians today: New insights on selection from the 5-COOP study. Current Gerontology and Geriatrics Research, 2010(120354), 1-9.

Robine, J. M., \& Paccaud, F. (2005). Nonagenarians and centenarians in Switzerland, 18602001: A demographic analysis. Journal of Epidemiology and Community Health, 59(1), 3137.

Robine, Jean-Marie, \& Cubaynes, S. (2017). Worldwide demography of centenarians. 
Mechanisms of Ageing and Development, 165(B), 59-67.

Robine, Jean-Marie, \& Saito, Y. (2003). Survival Beyond Age 100 : The Case of Japan Survival Beyond Age 100 : The Case of Japan. Population and Development Review, 29(supplement), 208-228.

Robine, Jean-Marie, Saito, Y., \& Jagger, C. (2009). The relationship between longevity and healthy life expectancy. Quality in Ageing and Older Adults, 10(2), 5-14.

Robine, Jean-Marie, and Vaupel, J.W. 2001. "Supercentenarians: Slower Ageing Individuals or Senile Elderly?” Experimental Gerontology 36 (4-6): 915-30.

Rosenwaike, I. (1979). A New Evaluation of United States Census Data on the Extreme Aged. Demography, 16(2), 279-288.

Rosenwaike, I., \& Logue, B. (1983). Accuracy of Death Certificate Ages for the Extreme Aged. Demography, 20(4), 569-585.

Skytthe, Axel and Jeune, Bernard. 1995. Danish centenarians after 1800. In: B. Jeune and J. Vaupel (Eds). Monographs on Population Aging. 2:55-66. Odense: Odense University Press.

Thatcher, A. R. (1992). Trends in numbers and mortality at high ages in England and Wales. Population Studies 46 (3): 411-426.

Thatcher, A. R. (2001). The demography of centenarians in England and Wales. Population: An English Selection 13(1): 139-156.

Turra, Cássio M. 2012. Os limites do corpo: A longevidade em uma perspectiva demográfica. Rev. UFMG 19(1): 156-181.

Siegel, J.S. and Passel J. S. (1976). New Estimates of the Number of Centenarians in the United States. Journal of the American Statistical Association 71(355), 559-566.

United Nations, Department of Economic and Social Affairs, Population Division (2017). World Population Prospects 2017, Online Edition.

United Nations, Department of Economic and Social Affairs, Population Division (2019). World Population Prospects 2019, Online Edition.

Vaupel, J. W., \& Gowan, A. E. (1986). Passage to Methuselah: some demographic consequences of continued progress against mortality. American Journal of Public Health, $76(4), 430-433$.

Vaupel, J.W., Carey, J. R., Christensen, K., Johnson, T.E., Yashin, A. I. et al. (1998). Biodemographic trajectories of longevity. Science 280(5365) 855-60.

Wang, Z., Zeng, Y., Jeune, B., \& Vaupel, J. W. (1998). Age validation of Han Chinese centenarians. Genus, 54(1-2), 123-141.

Wilmoth, J. (1995). The Earliest Centenarians: a statistical analysis. In: Jeune, B., Vaupel, J.W. (Eds.). Exceptional Longevity: From Prehistory to the Present. Odense University Press, Odense, 125-169.

Wilmoth, J. and Lundström, H. (1996). Extreme Longevity in Five Countries Presenteation of Trends with Special Attention to Issues of Data Quality. European Journal of Population 12, 63-93. 
List of Tables

1 Number of centenarians in Brazil: census and indirect estimates, 1900-2000........22 
Table 1. Number of centenarians in Brazil: census and indirect estimates, 1900-2000.

\begin{tabular}{|c|c|c|c|c|c|c|c|c|c|c|}
\hline \multirow{3}{*}{ Year } & \multicolumn{4}{|c|}{ Men } & \multicolumn{4}{|c|}{ Women } & \multicolumn{2}{|c|}{ Sex Ratio } \\
\hline & \multirow{2}{*}{ Census } & \multicolumn{3}{|c|}{ Estimated } & \multirow{2}{*}{ Census } & \multicolumn{3}{|c|}{ Estimated } & \multirow{2}{*}{ Census } & \multirow{2}{*}{ Estimated } \\
\hline & & Average & Minimum & Maximum & & Average & Minimum & Maximum & & \\
\hline 1900 & 2,047 & 0 & 0 & 1 & 2,391 & 1 & 0 & 1 & 0.86 & 0.62 \\
\hline 1920 & 2,625 & 1 & 0 & 2 & 4,102 & 2 & 0 & 3 & 0.64 & 0.46 \\
\hline 1940 & 2,817 & 5 & 0 & 11 & 4,999 & 21 & 3 & 51 & 0.56 & 0.22 \\
\hline 1950 & 3,290 & 7 & 2 & 13 & 6,399 & 22 & 5 & 46 & 0.51 & 0.33 \\
\hline 1960 & 3,483 & 12 & 3 & 21 & 6,393 & 33 & 9 & 66 & 0.54 & 0.38 \\
\hline 1970 & - & 22 & 5 & 48 & - & 65 & 17 & 146 & - & 0.34 \\
\hline 1980 & 3,545 & 35 & 7 & 99 & 6,705 & 103 & 27 & 256 & 0.53 & 0.34 \\
\hline 1990 & 4,253 & 48 & 15 & 115 & 8,773 & 168 & 54 & 353 & 0.48 & 0.29 \\
\hline 2000 & 10,423 & 180 & 38 & 393 & 14,153 & 739 & 198 & 1,334 & 0.74 & 0.24 \\
\hline
\end{tabular}

Note: The Brazilian Bureau of Census has not published the number of centenarians for 1970, only the population 90 years and older.

Source: Census Data. Calculations by the authors 


\section{List of Figures}

1 Life expectancy at birth and prevalence of centenarians: Brazil and selected countries,

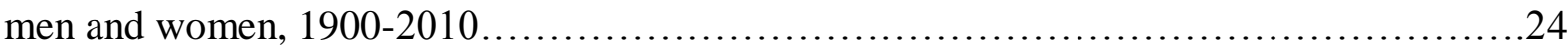

2 Ratio of the number of centenarians recorded in the census and indirectly estimated according to different parameters: Brazil, men and women, 1900-2000. 25

3 Life table survivorship ratios calculated from selected mortality schedules: Brazil, men and women, 1900-2000 .26 
Fig.1. Life expectancy at birth and prevalence of centenarians: Brazil and selected countries, men and women, 1900-2010

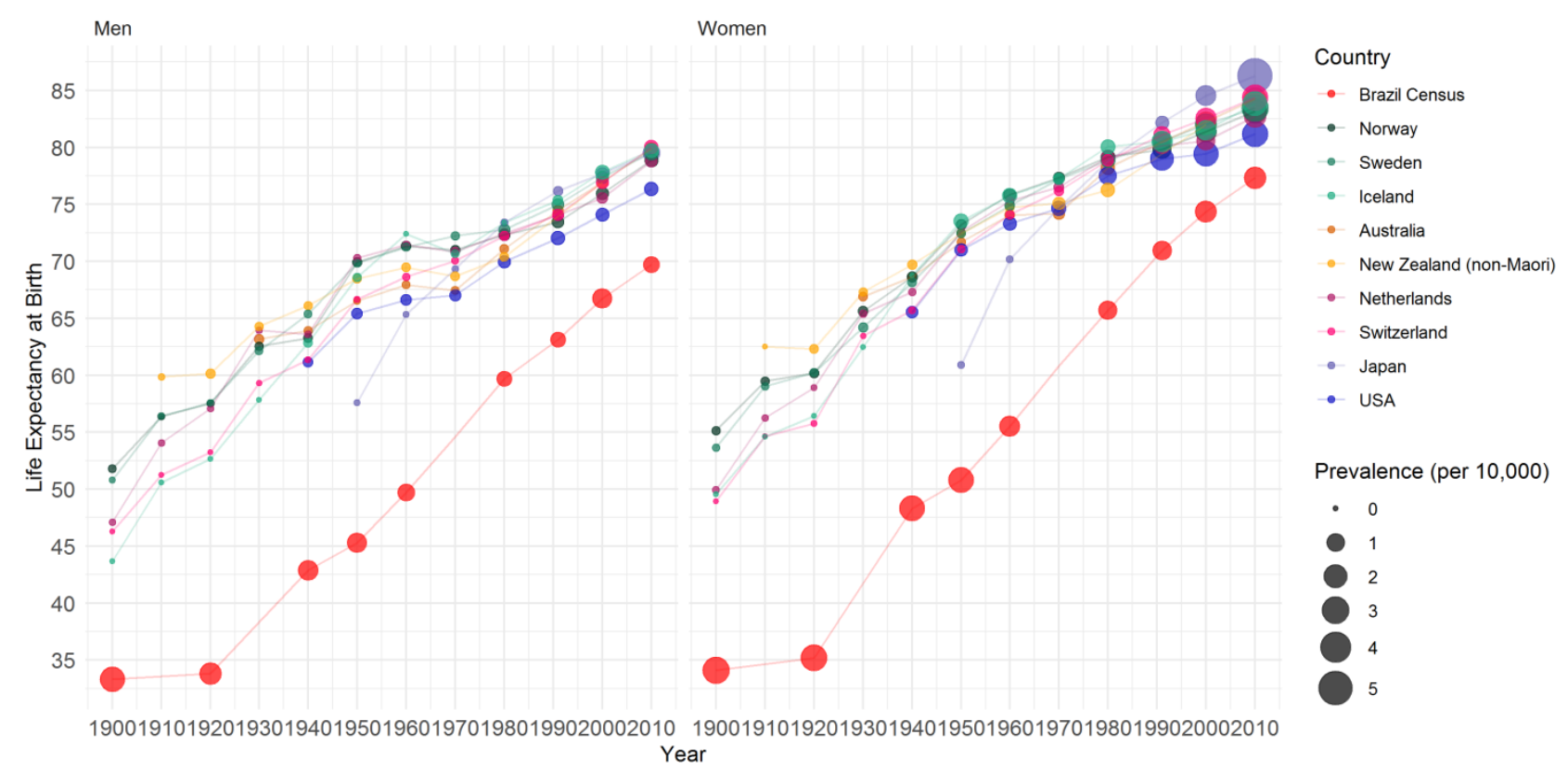

Source: HMD (2019) and Brazilian Census Data 
Fig.2. Ratio of the number of centenarians recorded in the census and indirectly estimated according to different parameters: Brazil, men and women, 1900-2000

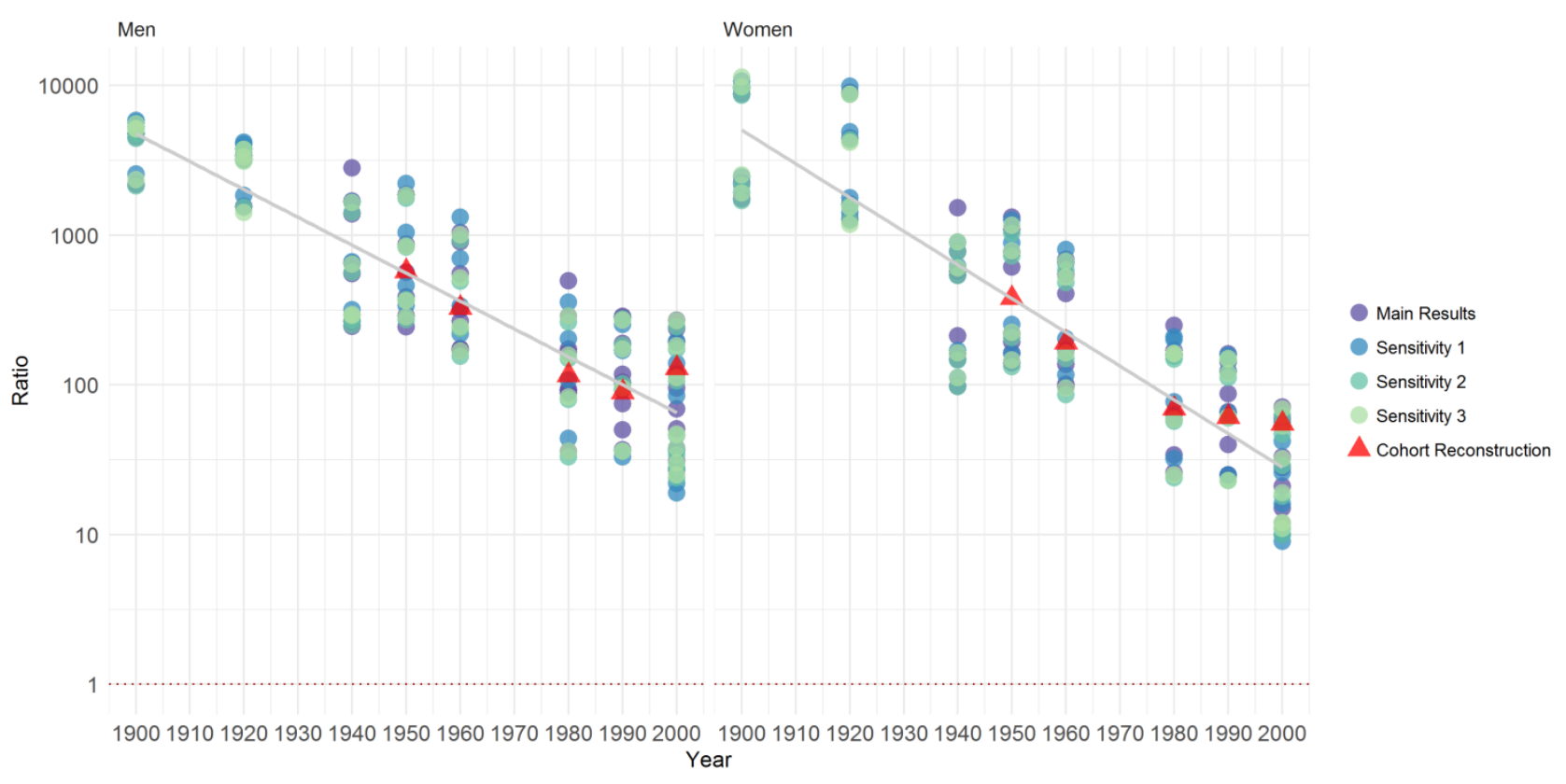

Notes: The main results and sensitivity analysis are based on the variable-r method. The lower limit age group is equal to 50-59 for the main results, and both sensitivity 1 and 2 . It is equal to $60-69$ for sensitivity 3. The open age interval for the calculation of the growth rates is equal to $90+$ for both the main results and sensitivity 3 , and equal to $80+$ for sensitivity 1 and $100+$ for sensitivity 2 . The dotted line corresponds to an equal number of centenarians recorded in census and indirectly estimated. Source: Census Data. Calculations by the authors 
Fig.3. Life table survivorship ratios calculated from selected mortality schedules: Brazil, men and women, 1900-2000

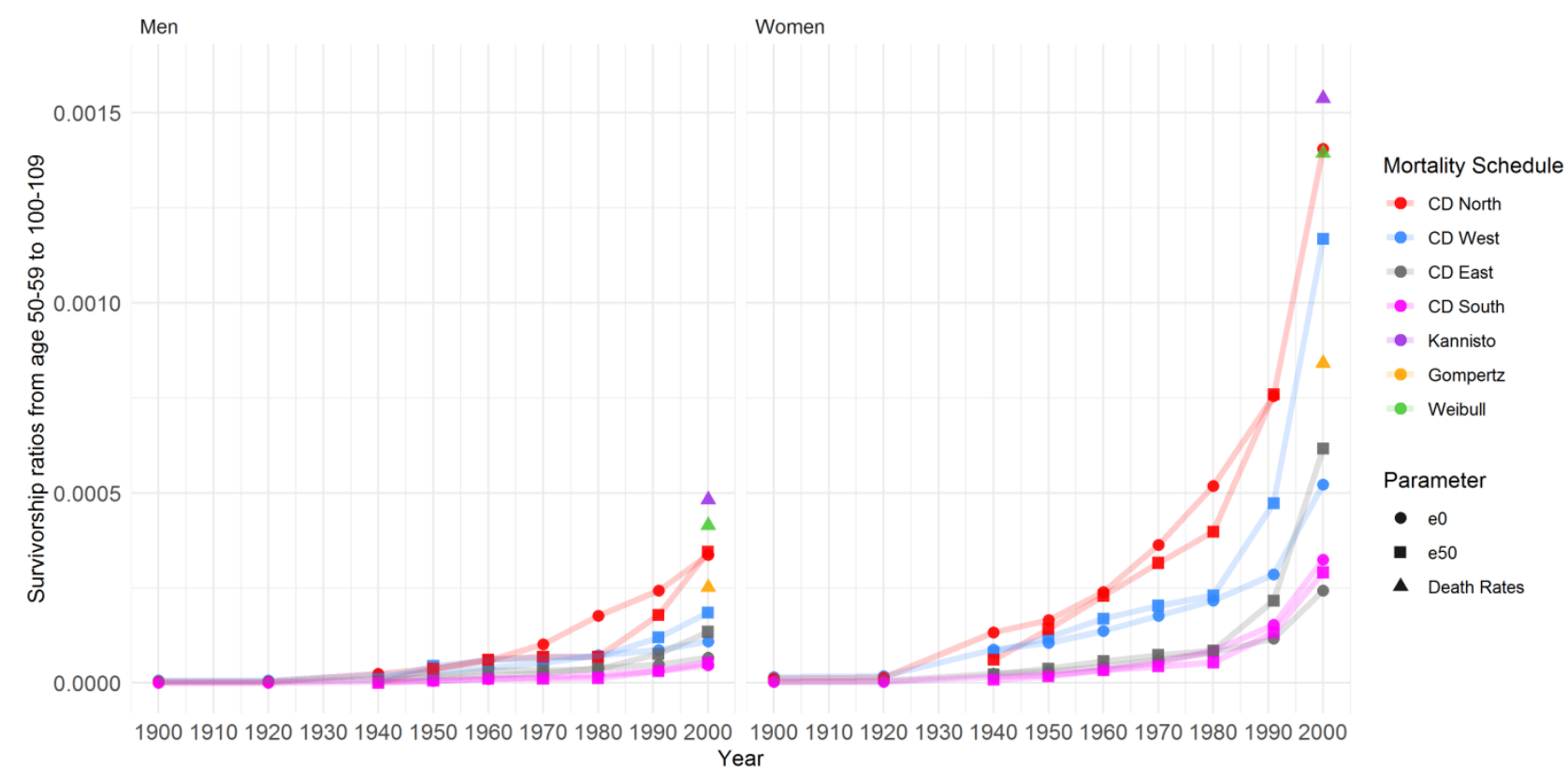

Source: Calculations by the authors 